DOI: 10.5752/P.2237-8871.2019v.19n.31p.36

\title{
Sociabilidade, sociedades de ideias e práticas associativas modernas
}

Sociability, societies of ideas and modern associative practices

Fausto Henrique Gomes Nogueira ${ }^{1}$

RESUMO: O intuito deste artigo consiste em identificar dois conceitos pouco manejados pelos historiadores e que podem servir como um importante quadro de referências para pesquisas na área de História: sociedades de pensamento - ou sociedades de ideias - e sociabilidades. A partir da formulação de autores como JeanPierre Bastian e Maurice Agulhon, procuramos demonstrar como esses conceitos se articulam no entendimento de práticas associativas ligadas a grupos sociais minoritários, como os espíritas.

Palavras-chave: sociabilidade, sociedades de ideias, espiritismo.

ABSTRACT: The aim of this article is to identify two concepts little handled by historians and that can serve as an important reference framework for researches in the History field: societies of thought - or societies of ideas - and sociabilities. From the formulation of authors such as Jean-Pierre Bastian and Maurice Agulhon, we try to demonstrate how these concepts are articulated in the understanding of associative practices linked to minority social groups, such as Spiritists.

Keywords: sociability, societies of ideas, spiritism.

O século XVIII presenciou, dentre tantas transformações, o advento de uma nova sociabilidade na Europa, produto das ideias ilustradas e sustentada pelo aparecimento de novas associações, como os clubes políticos, cafés, lojas maçônicas, círculos, entre outros. Essas sociedades compartilhavam algumas características semelhantes, pois estavam ancoradas em uma "adesão individual, voluntária, opcional e flexível” (AYMARD, 1991, p. 457), que, com o tempo, influenciaram parte considerável da sociedade. Elas reuniam indivíduos interessados em relações sociais

\footnotetext{
${ }^{1}$ Doutor em História Social pela Universidade de São Paulo (USP). Professor do Instituto Federal de Educação, Ciência e Tecnologia de São Paulo
} 
horizontais e no livre-pensamento, inspirados nos princípios iluministas e que destoavam da sociabilidade dominante, ancorada na hierarquização da sociedade em ordens, no espírito de corpo e no absolutismo monárquico.

Essas novas sociedades funcionavam como um local de conversação e debate, sustentadas em princípios de igualdade social, no qual as pessoas com os mesmos interesses e objetivos se encontravam em um ambiente laico ou religioso, unidos por laços de afinidade. Representaram, assim, uma forma alternativa de associação e uma ruptura com as instituições tradicionais como a família e o Estado.

Maurice Aymard (1991) afirma que essas sociedades significaram a emergência na sociedade contemporânea de novas práticas de amizade e convivialidade e comportaram diferentes estratégias e laços de solidariedade entre os indivíduos. Essas transformações auxiliaram em uma nova estruturação do espaço social e uma mudança nas formas de sociabilidade, ainda que fosse uma sociabilidade exclusivamente masculina, pois as novas associações excluíram a participação das mulheres e, inicialmente, era característica das classes médias, representando, portanto, uma sociabilidade burguesa. Esse modelo teria nascido na Inglaterra, com os clubes, ainda no século XV, e conheceu sua difusão nos séculos posteriores (1991, p. 481). Desse modo, foram fundamentais na disseminação de novas ideias e comportamentos para a sociedade da época.

O objetivo é o de uma sociabilidade muito genérica que tenderá a restringirse para especializar-se na reflexão política ou nas discussões literárias, ou mais ainda nos lazeres das classes mais abastadas. Associação livre de qualquer obrigação e sem outro objetivo além de si mesma, o clube decide ignorar os laços com a família e estabelece no estado puro um novo modelo de sociabilidade restrita. Não há sigilo, nem iniciação, nem programa. Tampouco há referência à fraternidade. Nem compromisso com relação a pessoas, e sim a adesão de um simples código de conduta idêntico para todos os membros, que não proíbe nem impõe nenhuma relação preferencial com nenhum deles. A convivialidade libera-se das obrigações da amizade e da família. (AYMARD, 1991, p. 484)

\section{Sociabilidades e construção do espaço público}

Para o entendimento da construção do campo conceitual das sociabilidades é fundamental as propostas teóricas de Maurice Agulhon (1926-2014). O autor evidencia a importância do conceito de sociabilidade no prefácio à $2^{\mathrm{a}}$ edição de sua obra, publicada em 1984, intitulada Pénitents et francs-maçons de l'ancienne Provence: essai 
sur la sociabilité méridionale (Paris, Fayard) ${ }^{2}$. Neste estudo, Agulhon analisa as formas associativas na região da Provença, particularmente a transição das confrarias para a franco-maçonaria, mostrando como elas se entrecruzaram com a vida cotidiana daquela sociedade. Ao estudar a sociabilidade construída a partir destes grupos, apresenta a existência de um "caráter" do povo, o que denominou de "sociabilidade meridional". Posteriormente, ampliou seus olhares para outros períodos e regiões, mostrando a sociabilidade como objeto da história.

O autor é considerado um dos principais nomes ligados à chamada Escola dos Annales $^{3}$. Peter Burke assinala que ele é um dos historiadores que mais se dedicaram à história política e aos estudos de história contemporânea com uma variada produção acadêmica, parte dela ligada aos estudos sobre a sociabilidade (BURKE, 1991, p. 72). Michel Vovelle destaca a importância de Agulhon para os estudos relacionados à História das Mentalidades, principalmente ao indicar o "caráter operatório" desse conceito, tendo em vista o surgimento de diversos trabalhos norteados pelas discussões proporcionadas por ele (VOVELLE, 2004, p. 238).

Vovelle afirma que a sociabilidade já havia sido examinada no século XIX por alguns historiadores, com um sentido ainda bastante impreciso e sob uma determinada leitura conservadora (VOVELLE, 2004, p. 226). Nesse momento, não era explorada de uma forma conceitual, mas sim utilizada de forma mais ou menos livre, com o intuito de revelar a atitude do viver em sociedade; era evocada em um sentido lato, portanto, para explicitar as relações entre os indivíduos e uma determinada característica da vida em sociedade, podendo significar vários elementos como as formas de interação social que ocorrem na vida coletiva das sociedades, sejam elas públicas, privadas, formais, informais etc. $^{4}$

\footnotetext{
${ }^{2}$ A primeira versão da obra data de 1966 e seu título original era La sociabilité méridionale: confréries et associations dans la vie collective en Provence orientale a la fin du XVIIIe siècle. Em que pese a importância desse livro, nota-se o fato de nunca ter sido traduzido para o português, bem como toda a obra do autor dedicada ao conceito de sociabilidade. Talvez possa ser essa uma das razões das suas conceituações terem sido pouco exploradas pelos historiadores brasileiros. Para algumas das obras do autor que discutiram o conceito de sociabilidade ver: AGULHON, Maurice. Introduction: La sociabilité est-elle objet d'histoire? In: FRANÇOIS, Étienne (org.). Sociabilité et société bourgeoise en France, en Allemagne et en Suisse, 1750-1850. Paris: Editions Recherche sur les Civilisations, 1986; La sociabilidad como categoria histórica. In: FUNDACIÓN MARIO GÓNGORA. Formas de sociabilidad en Chile. 1840-1940. Santiago de Chile: Fundación Mario Góngora: Editorial Vivaria, 1992; Historia vagabunda. Etnologia y política en la Francia contemporânea. México DF: Instituto Mora, 1994; El círculo burgués. La sociabilidade en Francia, 1810-1848. Buenos Aires: Siglo Veintiuno, 2009.

${ }^{3}$ Ver BURKE, Peter. A revolução francesa da historiografia: Escola dos Annales 1929-1989. São Paulo: Editora da UNESP, 1991, p. 7 e seg.

${ }^{4}$ BERNALDO, Pilar González. Presentación: Maurice Agulhon, un historiador de las mentalidades políticas. In: AGULHON, Maurice. El círculo burgués. Op. Cit., p. 15.
} 
Dessa maneira, é notória a contribuição de Agulhon nos estudos históricos a partir da construção de um conceito até então menosprezado pela historiografia e na articulação que ele efetua em seus estudos com outras ciências sociais como a sociologia, a antropologia e a etnologia. Sua abordagem amplia as formas de utilização das sociabilidades, renovando as pesquisas na área ao destacar as formas da vida associativa em determinados espaços e tempos específicos. Nos anos posteriores à publicação de seu clássico estudo, ele procurou delinear as possibilidades de utilização desse conceito, inserindo-o de forma inequívoca como categoria fundamental para o trabalho do historiador. Dessa forma, se não podemos afirmar que ele criou o conceito de sociabilidade, definitivamente foi o pioneiro na sua utilização. Desde meados dos anos 1960, inúmeros historiadores mergulharam nesse campo investigativo, prosseguindo nas veredas abertas por ele.

Esse conceito expressaria uma condição histórica dos grupos sociais, pois cada qual possui suas formas específicas de sociabilidade, que o historiador deve levar em consideração em sua análise. As pessoas, enquanto seres sociáveis se reúnem para interagir com outros semelhantes identificados por múltiplos objetivos, seja no nível societal ou em associações formadas para determinados objetivos. Os homens constroem, assim, comportamentos coletivos, relações de afinidade, correspondências mútuas, sensibilidades; estabelecem, assim, através do contato com o outro, sistemas de relações e de identidades. Em suma, os indivíduos ao viverem em sociedade criam vínculos, construindo formas de pertencimento e solidariedades.

De lá para cá, o conceito foi ressignificado e ampliado com novos estudos, inclusive, por parte de Agulhon, que transitou das práticas associativas para um campo mais abrangente, a sociabilidade burguesa que se desenvolveu no século $\mathrm{XIX}^{5}$. Anteriormente preocupado com as confrarias católicas e a maçonaria, voltou-se para os "círculos" procurando demonstrar que este tipo de prática associativa é tipicamente burguesa e ocorre em sociedades urbanas: a sociabilidade daí construída é elemento identitário dessa classe. Nesses espaços coletivos, onde se articula uma sociabilidade intermediária entre o salão e a cultura popular, os homens se reuniam para participar de uma atividade não lucrativa, mas voltada ao ócio, como ler periódicos, conversar, beber, jogar etc. Nesse aspecto, diferiam da sociabilidade hierárquica reinante nos salões

\footnotetext{
${ }^{5}$ AGULHON, Maurice. El círculo burgués. Op. cit.
} 
aristocráticos, frequentados por homens e mulheres da elite europeia e caracterizados pela vivência de uma moralidade específica (AGULHON, 2009, p. 40-51).

Esse conceito mostrou-se viável para se compreender determinadas especificidades da realidade social, na medida em que permite desvelar comportamentos e atitudes que surgiram a partir de práticas relacionais e que são características de grupos específicos, estabelecendo, daí, fronteiras entre as classes sociais; sendo que algumas destas classes se apresentaram, no século XIX, como portadoras da “civilização". Essas discussões representaram uma forma inovadora de se enxergar a modernidade, a modernização econômica e seu impacto nos modos de viver das pessoas, mesmo porque Agulhon procurou relacionar a emergência de novos valores e atitudes com a ascensão das classes médias.

Essas sociabilidades modernas estão na origem das novas regras sociais e comportamentais, pautadas por uma ideia de civilidade e ancoradas no liberalismo e no individualismo, representando uma forma de transposição do ideário moderno ao nível societal. A modernização da sociabilidade, a partir deste viés, passaria, necessariamente, pelo círculo; através deste, a burguesia em ascensão poderia adquirir maior projeção social.

La idea de civilización se constituyó en uno de los horizontes principales de las élites en el siglo XIX, y se convirtió en un deber ser al cual tenían que entregarse todos los esfuerzos del estado y de la sociedad. Desde esta perspectiva, la sociabilidad era una condición y a la vez un resultado que implicaba necesariamente un grado determinado de civilización; sin embargo, no era ésta una característica compartida por toda la sociedad. (MARTÍNEZ, 2010, p. 27)

O círculo se desenvolveu como espaço informal de encontro, principalmente nas pequenas cidades provincianas que possuíam poucos lugares para encontros, como os cafés; posteriormente, alguns se transformaram em associações formais, não sem tensões e conflitos com as autoridades. Nestes se desenvolveu um tipo de associação pública que permitia a saída de homens com bens materiais e interesses políticos e ideológicos de sua vida privada para se encontrarem com seus pares, operando uma mudança de mentalidade fundamental na construção de sua identidade, na medida em que a vivência em comum legitimava determinados discursos e valores que distinguiam esses grupos (AGULHON, 2009, p. 149-153). Essas práticas e representações culturais tiveram uma rápida disseminação nas primeiras décadas do século XIX. Assim,

Desde esta perspectiva, la sociabilidad fue una característica con la cual se identificaron y se definieron las élites, que establecieron y normalizaron los 
espacios - físicos y sociales - en los cuales eran puestas en juego las características fundamentales de la civilización: normas sociales y buenas maneras, además de un amplio repertorio escénico y teatral, que configuraban un capital simbólico y social basado en una estética particular (MARTÍNEZ, 2010, p. 27).

\section{Sociabilidade e sociedades de ideias}

Essas reflexões iniciais acerca das associações surgidas a partir da ascensão de novas classes sociais e de novas sociabilidades nos conduzem às discussões realizadas por outros historiadores que se debruçaram sobre essa temática. Augustin Cochin (1876-1916), ao que parece, foi o primeiro a chamar a atenção para o que ele denominou de "sociedades de pensamento"6. Sua obra busca compreender as origens da Revolução Francesa e, para isso, privilegia a função dessas sociedades na condução do processo revolucionário, particularmente em relação ao jacobinismo. Muitas de suas conclusões foram descartadas pelos historiadores e sua obra permaneceu esquecida, até que François Furet recupera parte de suas formulações e o emprego do conceito de "sociedades de pensamento", o que chamou a atenção de alguns historiadores.

Para Furet, Cochin percebeu algumas questões históricas importantes, como o advento de uma nova sociabilidade política que, antes minoritária, acabou influenciando decisivamente a sociedade com a emergência da Revolução Francesa (FURET, 1989, p. 53). O autor a denomina de "sociabilidade democrática", a partir da qual os homens vivenciaram práticas igualitárias no interior das associações. Essa sociabilidade seria originária de instituições como os cafés, círculos, sociedades literárias, academias e lojas maçônicas, isto é, "sociedades de pensamento" que representariam uma nova forma de associação instaurada de forma sub-reptícia na sociedade, funcionando independente do poder político (FURET, 1989, p. 54-55).

No interior destas sociedades de pensamento florescia o debate e a circulação de novas ideias, influenciando o seu entorno ao proporcionar formas de associação liberal em uma sociedade sustentada por um ordenamento hierárquico. Elas expressaram, portanto, o choque entre dois modelos de sociedade: a sociedade corporativa

\footnotetext{
${ }^{6}$ Embora em suas conclusões Cochin seja crítico em relação ao papel desempenhado pelas sociedades de pensamento quanto à Revolução Francesa, destacou algumas características essenciais dessas associações. Para essa questão ver: COCHIN, Augustin. Les sociétés de pensée et la démocratie moderne. Paris: PonNourrit, 1921. Disponível em: http://misraim3.free.fr/divers2/SOCIETES.PDF. Acesso em: 16 jan. 2018.
} 
determinada pela ausência de participação política pelo conjunto da sociedade, e a democrática, ancorada no individualismo, nos direitos naturais e no livre-pensamento. Nesse aspecto, Furet define:

O que é uma sociedade de pensamento? É uma forma de socialização cujo princípio consiste em que seus membros, para aí desempenharem seu papel, devem despojar-se de qualquer particularidade concreta e de sua existência social real. O contrário do que no Antigo Regime era chamado de 'corpos', definidos por uma comunidade de interesses profissionais ou sociais, vividos enquanto tal. A sociedade de pensamento é caracterizada, para cada um de seus membros, somente pela relação com as ideias, e é nisso que ela prefigura o funcionamento da democracia. Pois a democracia também igualiza os indivíduos em um direito abstrato, que basta para constituí-los: a cidadania, que engloba e define para cada um sua parte da soberania popular (1989, p. 185-186).

Dos historiadores que se dedicaram às discussões referentes ao significado e importância do conceito de sociedades de pensamento, procurando aplicá-lo a determinadas realidades históricas, Jean-Pierre Bastian é um dos mais destacados? Tendo como temática fundamental a história mexicana nos séculos XIX e XX, o autor nos adverte sobre o pouco interesse que a historiografia da América Latina dedicou a esse campo de estudos, que abarca as modernas formas de associação como lojas maçônicas, clubes liberais, mas também grupos protestantes e espíritas considerados por ele como sociedades de ideias por compartilharem ideários e práticas pertencentes à modernidade (1990, p. 7) ${ }^{8}$. De acordo com Bastian, uma das possíveis frentes de pesquisa nos estudos históricos consistiria em entendê-las como sociedades que constituíram redes informais e frentes liberais que, mais do que suas participações evidentes no campo religioso, atuaram no campo político. O autor observa que, neste campo de pesquisa, os historiadores prestaram mais atenção à maçonaria, mas não levaram em consideração uma frente ampla anticlerical que outros grupos como os protestantes e espíritas constituíram ao longo de sua jornada ${ }^{9}$. Para tanto, seria

\footnotetext{
${ }^{7}$ Bastian utiliza o termo "sociedades de ideias" no lugar de sociedades de pensamento.

${ }^{8}$ Bastian, ao estudar as sociedades protestantes que adentraram no México a partir de meados do século XIX, busca contemplar em suas análises, também, as sociedades espíritas e defende que, embora possuíssem projetos culturais específicos, podem ser consideradas sociedades de ideias, na medida em que estavam engajadas na defesa do livre pensamento e na disseminação de ideias modernas, como o racionalismo, o cientificismo, o evolucionismo e o progresso, criticando o pensamento católico conservador e defendendo uma sociedade laica. Para essa questão ver: BASTIAN, Jean-Pierre (org.). Protestantes liberales y francmasones. Sociedades de ideas y modernidade em América Latina, siglo XIX. México D. F.: Fondo de Cultura Económica, 1990.

${ }^{9}$ Sobre essa possível frente comum entre protestantes e espíritas, no caso brasileiro, David Gueiros Vieira nos informa que ocorreram vários incidentes na segunda metade do século XIX nos quais os espíritas fizeram causa comum com os protestantes contra os "ultramontanos", pois estes declararam ilegais ambas as práticas religiosas. $\mathrm{O}$ autor revela, inclusive, alguns fatos que demonstram a ocorrência, embora diminuta, de um trânsito religioso entre espíritas e protestantes. Ver VIEIRA, David Gueiros. $O$
} 
fundamental levar a cabo estudos que ultrapassem a peculiaridade de cada associação e que a insiram em um movimento global de mudança social e política na qual elas estavam inseridas (1990, p. 7-8).

Desse modo, Bastian propõe a possibilidade de se lançar luz à história política da América Latina a partir do estudo de minorias que, embora se organizassem em sociedades de cunho religioso, caso de protestantes e espíritas, auxiliaram na laicização e na introdução de ideias liberais nos países do continente, em virtude das redes constituídas em oposição aos conservadores e à Igreja Católica, auxiliando no entendimento das "mutações políticas" que ocorreram no continente $\left(1990\right.$, p. 9) ${ }^{10}$. Essas sociedades seriam, assim, atores políticos que teriam oferecido importantes contribuições. O autor critica as interpretações cristalizadas da historiografia e que oferecem uma leitura meramente institucional de suas contribuições e

[...] que se limitaban a ver en el protestantismo una mera injerencia foránea o una conspiración desnacionalizadora; en el espiritismo, un mero esoterismo especulativo; y en la masonería, un fenómeno que fue importante durante la primera mitad del siglo, y decadente luego. [...] Estas formas de socialización no fueron únicamente un frente anticatólico, sino más bien redes prepolíticas portadoras de la modernidad en contra de la sociedad profunda, corporativista, que - por cierto - encontró en el catolicismo romano, y en su modelo aristotélico-tomista de sociedad patrimonial, su mejor baluarte. (BASTIAN, 1990, p. 9)

Para Bastian, essas sociedades protestantes e espíritas pautaram as suas atuações na América Latina a partir de um ideário em comum: defesa do livre-pensamento, crença na democracia, liberalismo, em suma, valores modernos, além da edificação de um importante movimento anticlerical que auxiliou na construção de uma frente em comum contra a Igreja Católica (BASTIAN, 1990, p. 7-8). Nessa acepção, teriam sido dois os motivos do sucesso destas sociedades: uma "comunhão ideológica", isto é, uma grade de ideias modernas que serviram como base para seus discursos, inspiração para muitas pessoas se reunirem e discutir seus significados, e a existência de grupos sociais inseridos em um mundo em processo de modernização e que pretendiam apreender este

protestantismo, a maçonaria e a questão religiosa no Brasil. Brasília: Editora Universidade de Brasília, 1980, p. 54 e seg.

${ }^{10}$ Eliane Moura Silva também nota, para o caso brasileiro, a existência de uma rede anticlerical entre o final do século XIX e início do XX, que reunia vários segmentos como protestantes, espíritas e maçons. A autora utiliza as discussões realizadas por Bastian, considerando o livre pensamento e o anticlericalismo como características fundamentais dessas sociedades (1997). 
mundo a partir destes ideários modernos, rompendo com o pensamento tradicional cuja base era o catolicismo de feição ultramontana.

O autor denomina essas associações de "minorias liberais", que serviram como sustentáculo dos projetos liberais em curso, quando se levantaram em vários países da América Latina movimentos antiliberais, apoiados ideologicamente por uma Igreja Católica em rápido processo de romanização e que se posicionou contrária aos projetos modernos. $\mathrm{O}$ anticlericalismo dessas sociedades, principalmente para o caso mexicano, foi importante e serviu como instrumento para encaminhar o "liberalismo radical" que estava sendo suplantado pelo liberalismo conservador com contornos autoritários e que não considerava as demandas democráticas de participação. Para o autor, protestantes e espíritas participaram dessas frentes anticatólicas, apoiados pelos maçons, auxiliando na construção de um espaço político liberal, portador das reivindicações da modernidade (BASTIAN, 1990, p. 9-12).

Como em relação às sociedades de ideias fundadas na Europa e mencionadas acima, a conversão do sujeito dava-se de forma voluntária, a partir da livre associação, atraídos pelo ideário propagado por elas. Uma organização de base democrática, onde os pares eram considerados iguais, pautada pela discussão de ideias e até pela divulgação de práticas de civismo (BASTIAN, 1999, p. 310).

[...] En contra de esta sociedad tradicional, de Antiguo Régimen, las sociedades de ideas fueron portadoras de la modernidad, en el sentido de que estructuraban nuevas formas de organización de lo social, ya no centradas sobre los antiguos cuerpos, sino en el individuo como actor político y social. Como escribe Furet: fueron una forma de socialización cuyo principio consiste en que sus miembros deben, para conservar en ella su papel, despojarse de toda particularidad concreta y de su real existencia social. La sociedad de ideas está caracterizada por el hecho de que cada uno de sus miembros tiene solamente una relación con las ideas, con los fines. En este sentido estas sociedades anticipan el funcionamiento de la democracia, pues ésta iguala también a los individuos dentro de un derecho abstracto que es suficiente para constituirlos en ciudadanía, que contiene y define la parte de soberanía popular que le corresponde a cada uno (BASTIAN, 1990, p. 7-8).

O autor transpõe essa discussão, originalmente pensada para a situação francesa anterior à Revolução Francesa, para a realidade da América Latina. Dessa maneira, essas sociedades ofereceram o seu contributo para o rompimento com a sociedade tradicional, pois teriam representado uma espécie de "laboratório", a partir do qual as minorias políticas ativas construíram alternativas sociais e políticas significativas para as reformas liberais no continente, pois “[...] en estas nuevas asociaciones se forjó una 
renovada visión de la sociedad de tipo igualitario, fundada en la autonomía del sujeto social individual como actor democrático" (BASTIAN, 1990, p. 8).

Em seu estudo sobre as sociedades protestantes fundadas a partir da atividade missionária estadunidense no México e sua participação na revolução mexicana, entre 1872 e 1911, Bastian revela o rápido florescer dessas sociedades e sua luta pela "ruptura simbólica e política com a sociedade corporativa e patrimonial herdada da colônia" (1989, p. 14). Os protestantes, atuando em rede com maçons e espíritas, foram significativos na construção de uma "pedagogia liberal" que auxiliou na inculcação de uma cultura política moderna, em um momento de supremacia de um liberalismo conservador no país, principalmente pela atuação de Porfirio Díaz e sua política de conciliação com a Igreja Católica; essas sociedades, portanto, teriam contribuído na construção de um espaço organizativo antiporfirista (1989, p. 303).

O autor, assim, interessado em compreender a participação dessas sociedades na construção de uma sociabilidade moderna e liberal no México, procura fazer aproximações com outras realidades da América Latina, resguardadas as devidas especificidades nos processos históricos dos países. Ele busca evidenciar a atuação destes grupos minoritários que contribuíram para a desestabilização da sociedade ou na imposição de novos valores e práticas importantes na composição de um novo tecido social heterodoxo. Bastian prefere chamar as sociedades religiosas protestantes e espíritas de sociedades de ideias e não de seitas, na medida em que possuíam interesses específicos e:

[...] como porque ellas fueron más bién sociedades de ideas abiertas a la cultura y a la historia liberal que asimilaron y transmitieron. Además las obras de civilización (escuelas, hospitales) que fomentaron fueron constituidas con base en una relación abierta con la sociedad, en cuanto obras de una religión de vanguardia ideológica liberal. Al contrario, la secta se carateriza por el intento de elaborar una contra-sociedad que hace 'huelga' en la sociedad global en virtud de un repliegue sobre sí misma y por la falta de una relación con la cultura y con la historia que se refleja en una ideología anómica con fuerte contenido milenarista ahistórico que hace de la secta une religión del oprimido (BASTIAN, 1989, p. 16-17).

Por fim, o autor, além de abordar o protestantismo e o espiritismo mexicano como uma "ideologia dissidente", investiga sua função prático-social, considerando-a como uma forma de organização e associação específica, pois suas práticas e crenças representariam uma ruptura com as religiões hegemônicas (BASTIAN, 1989, p. 17). Os protestantes, assim como a maçonaria, as sociedades mutualistas e os espíritas 
significariam uma forma de associação moderna, o que conduziu muitas pessoas a vivenciarem essas experiências.

$\mathrm{O}$ fundamental nesse processo teria sido a postura que resultou no rompimento com o catolicismo dominante, dotado de um caráter corporativo e patrimonial, privilegiando o grupo sobre o indivíduo; enquanto as outras sociedades forjariam uma concepção moderna, pautada pela laicidade e por práticas associativas liberais, cuja conversão implicava a ruptura com os valores dominantes (BASTIAN, 1989, p. 17). Dessa forma, se produziria a tensão entre duas visões incompatíveis de mundo que se enfrentavam: a católica, ultramontana, corporativista, patrimonial e defensora da ordem social natural, e outra liberal, inspirada nos princípios de 1789, em busca tanto da liberdade do Estado da tutela da Igreja como da aplicação de princípios democráticos formais. Desse modo, objetivavam

[...] desprenderse del catolicismo para así erradicarlo y sustituirlo por valores religiosos y morales secularizados, inspirados en un cristianismo moderno, tipificado a su vez por el protestantismo ético forjador del individuo moral y socialmente responsable como sujeto de la acción política y social del Estado moderno (BASTIAN, 1989, p. 312).

Em suma, a existência dessas sociedades de ideias com seu conceito moderno de associação, distante das práticas corporativas tradicionais e partidárias de uma concepção secularizada e moderna de sociedade representariam, por si só, uma ruptura com a ordem social, ao considerar os indivíduos como atores sociais e, por isso, mais do que atividades religiosas tiveram uma função política; no caso mexicano, de oposição ao porfirismo e participação na revolução maderista.

Com efeito, o autor procura, assim, evidenciar o papel político desempenhado por essas associações e não apenas a discussão sobre suas ideias doutrinárias propriamente ditas e seu caráter especulativo. Seus trabalhos tem se dirigido à difusão das sociedades protestantes no México $^{11}$, cujas reflexões evidenciaram a possibilidade de se trabalhar com as sociedades de ideias de tipo religioso, como os protestantes e os espíritas, encontrando mediações entre o religioso (cultural) e o político.

Bastian também chama a atenção para a necessidade de se identificar a origem social dos participantes dessas sociedades e responsáveis pela disseminação de seus

${ }^{11}$ BASTIAN, Jean-Pierre. Los disidentes. Sociedades protestantes y revolución en México, 1872-1911. México, D.F.: Fondo de Cultura Económica/Colegio de México, 1989. BASTIAN, Jean-Pierre (org.). Protestantes liberales y francmasones. Sociedades de ideas y modernidad en América Latina. Op. cit; Protestantismos y modernidad latinoamericana: historia de unas minorías religiosas activas en América Latina. México, D. F.: Fondo de Cultura Económica, 1994. 
ideais, pois seriam homens originários de classes sociais em transição e que viviam em situação precária, sofrendo as transformações ocorridas no capitalismo nascente na América Latina ${ }^{12}$. Esses grupos sociais ansiavam por se enquadrar na sociedade, mas, ao mesmo tempo, se afastar de qualquer controle corporativo. Em suma, eram, na sua maioria, setores sociais médios que se identificavam com os processos de modernização ocorridos no país.

Essas considerações influenciaram raros trabalhos acadêmicos produzidos aqui no Brasil, entre os quais se destaca o de Fernando Antonio Peres ${ }^{13}$. Em sua tese de doutorado, Peres utiliza amplamente o conceito de sociedade de ideias, a partir das problematizações de Bastian, aliado à noção de ambiência, para estudar a atuação de João de Camargo Penteado, educador que foi diretor da Escola Moderna $N^{o} 1$ de São Paulo e que se notabilizou, também, pela sua atuação na imprensa anarquista e espírita.

O autor emprega o conceito de sociedade de ideias para abordar os grupos socialistas e anarquistas, evidenciando as relações estabelecidas com alguns grupos espíritas, seja sua atuação no espaço público paulista, a partir de iniciativas educacionais ou na imprensa periódica, seja por comungarem uma "tábua de valores" que funcionava como elemento aglutinador dessas sociedades, pautada pelos ideais das Luzes: valorização do indivíduo, postura ética, vivência democrática e crença na ciência (PERES, 2010, p. 13). Peres procurou evidenciar as estratégias de aproximação entre os grupos citados, percebendo o diálogo entre estes atores sociais, principalmente a partir de suas pautas em comum e seus mecanismos de legitimação social.

Dessa forma, a partir da trajetória de um educador que transitou entre grupos diferentes - anarquistas e espíritas - e que construiu o seu pensamento e prática pedagógica a partir desses diferentes ideários, Peres demonstra a possibilidade de se compreender as redes de relacionamento que eram construídas em São Paulo na Primeira República muito mais complexas e heterodoxas do que a historiografia tradicionalmente tem abordado.

João Penteado foi simultaneamente espírita e anarquista; pôde sê-lo sem grandes dissabores porque estas duas manifestações do pensamento

\footnotetext{
12 No caso mexicano seriam trabalhadores mineiros ou provenientes da indústria têxtil, da agricultura industrial e pequenos proprietários (BASTIAN, 1989, p. 15-16).

13 PERES, Fernando Antonio. Revisitando a trajetória de João Penteado: o discreto transgressor de limites. São Paulo, 1890-1940. São Paulo: FEUSP, 2010. Tese (Doutorado em Educação).
} 
ocidental, que se espalharam rapidamente na segunda metade do século XIX, são fruto da difusão das sociedades de ideias em regiões que tinham a questão da modernidade na agenda do dia - como era o caso do Brasil nos anos finais do Império e nos anos iniciais da Primeira República (PERES, 2010, p. 10).

Nesse sentido, o autor, como Bastian, procura valorizar as práticas forjadas pela atuação destes grupos e as novas formas de associação, representação e valores propostos, reveladores de transformações operadas na sociedade. Essas sociedades de ideias, irmanadas por essa "tábua de valores" auxiliaram na cristalização de novas formas de sociabilidade.

Essas associações tiveram, por fim, uma função pedagógica. Por representarem espaços alternativos na época, propagadores de práticas democráticas e de transformação do cidadão, facilitaram o entendimento do significado da esfera pública e de formas de participação política, auxiliando na construção de uma opinião pública e no entendimento de visões políticas alternativas.

Como visto, os conceitos de sociabilidade e de sociedade de ideias possuem uma amplitude e aplicabilidade enorme, correspondendo a várias expressões da vida social e permitindo a articulação com outros conceitos e noções. Uma de suas possibilidades é o estudo da vida associativa de determinadas sociedades de ideias considerando-se, obviamente, suas relações internas, projetos, doutrinas etc., mas, simultaneamente, suas relações com a sociedade, de acordo com as considerações realizadas por Agulhon e Bastian. Essas discussões se relacionam com o contexto das preocupações específicas da História Cultural em estudar correntes de ideias, mas não apenas as mais expressivas, mas, sim, aquelas produzidas por agentes que não pertencem à elite social ou intelectual de uma dada sociedade, os quais também são produtores de significados compartilhados por determinados grupos ${ }^{14}$.

Nessa mesma linha, Peter Burke chama a atenção para a produção de discursos realizados por determinados grupos sociais que expressam as representações de coletividades pertencentes à esfera social. Ele observa que Habermas ao evidenciar o conceito de esfera pública defendeu que os historiadores estudassem instituições informais como cafés, clubes, salões, academias etc., como redes de associações voluntárias e grupos de pressão política, isto é, "comunidades discursivas"; essas

\footnotetext{
${ }^{14}$ Para essa discussão ver: PESAVENTO, Sandra Jatahy. História \& história cultural. Belo Horizonte: Autêntica, 2008, p. 15 e seg.
} 
questões vão ao encontro dos conceitos de sociedades de ideias e sociabilidades discutidos acima (BURKE, 2012, p. 136).

Com efeito, os autores acima discutidos nos revelaram a importância de se compreender as novas formas associativas que surgiram no limiar da modernidade, como espaços construtores de sociabilidades e de transmissão de ideias modernas e sua importância na construção de um espaço público em sociedades em transição. Nesse sentido, é fundamental a compreensão das redes de sociabilidade construídas pelos intelectuais ligados a essas sociedades de ideias, facilitadoras da livre circulação desses projetos culturais e políticos defendidos. Embora sejam projetos alternativos formulados por grupos minoritários, que podemos denominar de "dissidentes", na expressão de Bastian, se relacionaram com outros grupos e projetos que partilhavam de um clima "moderno", construindo redes de sociabilidade, forjando práticas e representações que influenciaram parcelas da sociedade e interferindo no espaço público em vias de construção na sociedade paulista.

Nesse particular, o conceito de sociedades de pensamento, ou sociedades de ideias, nos possibilita pensar sobre instituições e agentes que contribuíram na construção e disseminação de determinados ideários e sociabilidades, rompendo com práticas e representações dominantes na sociedade. Isso demonstra uma outra forma de se compreender aspectos relativos à sociedades em vias de modernização e de secularização, a partir das iniciativas de pequenas sociedades que germinaram em um período de transição, no caso brasileiro, no período republicano, época de secularização da sociedade e pluralização do campo religioso brasileiro, mas ainda um meio patriarcal, conservador, católico, hierárquico e tradicionalista, cuja abordagem tem sido pouco explorada pela historiografia.

Em nossa tese de doutorado ${ }^{15}$ procuramos demonstrar que esse conceito é promissor ao se refletir sobre um catolicismo de cunho ultramontano que predominava na sociedade, ao mesmo tempo em que as novas doutrinas espiritualistas passaram a trazer novos valores religiosos e éticos, alicerçados em uma tradição iluminista que visava transformar a sociedade tradicional. Portanto, auxiliavam na difusão de uma cultura democrática e, no caso dos espiritualistas, de caráter cientificista e evolucionista.

15 NOGUEIRA, Fausto Henrique Gomes. Os espíritos assombram a metrópole: sociabilidades espiritualistas (espírita e esotérica) em São Paulo na Primeira República. São Paulo, 2015. Tese (Doutorado em História Social) - Faculdade de Filosofia, Letras e Ciências Humanas, Universidade de São Paulo. 
Seus participantes e leitores de seus periódicos experimentavam uma nova visão de sociedade calcada em um devir histórico progressista oposto à sociedade conservadora de então. Desenvolviam a ideia de livre pensamento, como representações e práticas que não coadunavam com o dogmatismo e o preconceito, isto é, distantes do pensamento católico conservador. Dessa maneira, difundiam o pensamento espiritualista, uma corrente iluminista, agregando letrados e pessoas de várias camadas sociais, que, a partir de práticas específicas, contribuíam para a construção de um Estado laico. 


\section{BIBLIOGRAFIA}

AGULHON, Maurice. El círculo burgués. La sociabilidade en Francia, 1810-1848. Buenos Aires: Siglo Veintiuno, 2009.

Historia vagabunda. Etnologia y política em la Francia contemporânea. México DF: Instituto Mora, 1994.

Pénitents et francs-maçons de l'ancienne Provence: essai sur la sociabilité méridionale. Paris: Fayard, 1984.

As sociedades de pensamento. In: VOVELLE, M. (org.). França Revolucionária (1789-1799). São Paulo: Brasiliense, 1989.

Visão dos bastidores. In: LE GOFF, Jacques et al. Ensaios de Ego-história. Lisboa, Edições 70, 1989b.

La sociabilidad como categoria historica. In: FUNDACIÓN MARIO GÓNGORA. Formas de sociabilidade em Chile 1840-1940. Santiago de Chile: Vivaria, 1992.

AUBRÉE, Marion; LAPLANTINE, François. A mesa, o livro e os espíritos: gênese, evolução e atualidade do movimento social espírita entre França e Brasil. Maceió: EDUFAL, 2009.

AYMARD, Maurice. Amizade e convivialidade. In: ARIÈS, Philippe; CHARTIER, Roger (org.). História da vida privada: da Renascença ao Século das Luzes. São Paulo: Companhia das Letras, 1991.

BACZKO, Bronislaw. Imaginação social. In: Enciclopédia Einaudi. AnthroposHomem. V. 5. Lisboa: Imprensa Nacional-Casa da Moeda, 1985.

BASTIAN, Jean-Pierre. Los disidentes. Sociedades protestantes y revolución en México, 1872-1911. México, D.F.: Fondo de Cultura Económica/Colegio de México, 1989.

Protestantismos y modernidad latinoamericana. Historia de unas minorías religiosas activas en América Latina. México D.F.: Fondo de Cultura Economica, 1994.

Introducción. In: BASTIAN, Jean-Pierre (org.). Protestantes liberales y francmasones. Sociedades de ideas y modernidad en América Latina, siglo XIX. México D.F.: Fondo de Cultura Económica, 1990.

Las sociedades protestantes y la oposición a Porfirio Díaz en México, 18771911. BASTIAN, Jean-Pierre (org.). Protestantes liberales y francmasones. Sociedades de ideas y modernidad en América Latina, siglo XIX. México D.F.: Fondo de Cultura Económica, 1990.

BURKE, Peter. História e Teoria Social. São Paulo: Editora Unesp, 2012. 
A revolução francesa da historiografia: Escola dos Annales 1929-1989. São Paulo: Editora da UNESP, 1991.

CANO, Gilberto Loaiza. Cultura política popular y espiritismo (Colombia, siglo XIX). Historia y espacio, Cali: Universidad del Vale, n. 32, 2009.

COCHIN, Augustin. Les sociétés de pensée et la démocratie moderne. Disponível em: $<$ http://misraim3.free.fr/divers2/SOCIETES.PDF>. Acesso em: 16 jan. 2018.

ELIADE, Mircea. Ocultismo, bruxaria e correntes culturais. Belo Horizonte: Interlivros, 1979.

FURET, François. Pensando a Revolução Francesa. Rio de Janeiro: Paz e Terra, 1989.

GONZÁLEZ-BERNALDO, Pilar. Presentación. In: AGULHON, Maurice. El círculo burgués. La sociabilidade en Francia, 1810-1848. Buenos Aires: Siglo Veintiuno, 2009.

GUARÍN-MARTÍNEZ, Oscar. La sociabilidad política: un juego de luces y sombras. Memoria y Sociedad. Bogotá, n. 14, v. 29, p. 25-36, jul. dez. 2010.

GUEREÑA, Jean-Louis. Espacios y formas de la sociabilidad en la España contemporánea. Hispania, n. 214, v. 63, p. 409-414, 2003.

HABERMAS, Jürgen. Mudança estrutural da esfera pública: investigações quanto a uma categoria da sociedade burguesa. Rio de Janeiro: Tempo Brasileiro, 2003.

ISAIA, Artur Cesar. Espiritismo, República e Progresso no Brasil. In: ISAIA, Artur Cesar; HOMEM, Amadeu Carvalho; SILVA, Armando Malheiro da (Coord.). Progresso e Religião. A República no Brasil e em Portugal (1889-1910). Coimbra: Imprensa da Universidade de Coimbra; Uberlândia: EDUFU, 2007.

NOGUEIRA, Fausto Henrique Gomes. Os espíritos assombram a metrópole: sociabilidades espiritualistas (espírita e esotérica) em São Paulo na Primeira República. São Paulo, 2015. Tese (Doutorado em História Social) - Faculdade de Filosofia, Letras e Ciências Humanas, Universidade de São Paulo.

PERES, Fernando Antonio. Revisitando a trajetória de João Penteado: o discreto transgressor de limites. São Paulo, 1890-1940. São Paulo: FEUSP, 2010. Tese (Doutorado em Educação).

PESAVENTO, Sandra Jatahy. História \& história cultural. Belo Horizonte: Autêntica, 2008

SILVA, Eliane Moura. O Espiritualismo no século XIX: reflexões teóricas e históricas sobre correntes culturais e religiosidade. Campinas: UNICAMP, $1997 \mathrm{~b}$.

Entre religião e política: maçons, espíritas, anarquistas e socialistas no Brasil por meio dos jornais A Lanterna e O Livre Pensador (1900-1909). In: ISAIA, Artur Cesar; MANOEL, Ivan Aparecido (orgs.). Espiritismo \& religiões afro-brasileiras. São Paulo: Ed. Unesp, 2012. 
TODOROV, Tzvetan. O espírito das Luzes. São Paulo: Editora Barcarolla, 2008.

VOVELLE, Michel. Ideologias e Mentalidades. São Paulo: Brasiliense, 2004. 